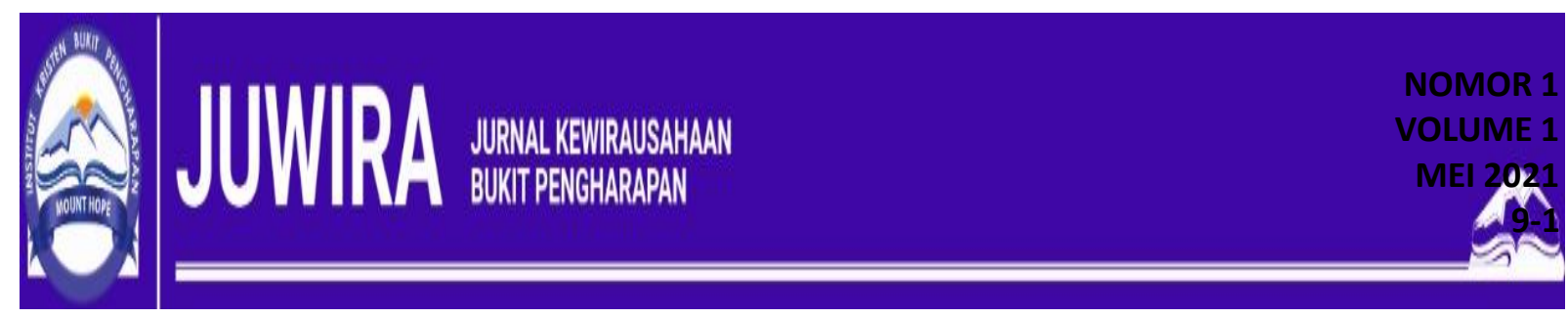

\title{
ANALISA MARKETING MIX PT. PANIN DAI-ICHI LIFE INDONESIA
}

Ade Citra ${ }^{1}$

Universitas Sahid, Jakarta

\begin{abstract}
Abstrak
Produk adalah apa saja yang diproduksi untuk memenuhi kebutuhan orang, bisa dalam bentuk jasa, barang, atau produk virtual. Tujuan dari penelitian ini adalah untuk menjelaskan proses terjadinya marketing mix yang ada di PT. PANIN DAI-ICHI LIFE INDONESIA secara detail. Metode yang digunakan dalam penelitian ini adalah penelitian kualitatif. Hasil penelitian adalah Strategi penerapan Marketing Mix di PT. PANIN DAI-ICHI LIFE INDONESIA Sudah sesuai dengan metode strategi hal itu bisa kita lihat dari Produk utama yang dipasarkan oleh PANIN DAI-ICHI LIFE adalah produk Asuransi yang bertujuan untuk memberikan perlindungan kepada seluruh masyarakat Indonesia. Media promosi yang digunakan oleh Panin Dai-Ichi Life Indonesia saat ini adalah menggunakan media serta platform digital. Dan begitu juga dari sisi harga, proses.
\end{abstract}

Kata-kata Kunci: Marketing Mix, Kualitatif, Asuransi

\begin{abstract}
Products are anything that is produced to meet people's needs, it can be in the form of services, goods, or virtual products. The purpose of this research is to explain the process of the marketing mix in PT. PANIN DAI-ICHI LIFE INDONESIA in detail. The method used in this research is qualitative research. The result of this research is the strategy of implementing the Marketing Mix at PT. PANIN DAI-ICHI LIFE INDONESIA Already in accordance with the strategic method, we can see that the main products marketed by PANIN DAI-ICHI LIFE are insurance products that aim to provide protection to all Indonesian people. The promotional media used by Panin Dai-Ichi Life Indonesia currently is using digital media and platforms. And so it is in terms of price, process.
\end{abstract}

Keyword: Marketing Mix, Qualitative, Insurance

\section{PENDAHULUAN}

Produk adalah apa saja yang diproduksi untuk memenuhi kebutuhan orang, bisa dalam bentuk jasa, barang, atau produk virtual. Di era digital ini produk tidak terbatas pada produk fisik atau jasa. Anda juga bisa menciptakan produk virtual seperti website, aplikasi, dan semacamnya. Unsur berikutnya dalam marketing mix yaitu Price atau harga adalah sejumlah uang yang dikeluarkan konsumen untuk menggunakan produk Anda. Harga yang terlalu rendah bisa membahayakan keberlangsungan bisnis. Di sisi lain, harga yang terlalu tinggi juga akan menyurutkan minat pembeli.

Place atau tempat adalah lokasi fisik tempat berjalannya bisnis atau kanal distribusi untuk mencapai target pasar. Sebuah bisnis memerlukan lokasi penjualan yang ideal untuk bisa menjangkau target pasar dengan mudah. Unsur marketing mix yang satu ini mencakup kantor pusat, gudang, pabrik, toko fisik, kantor cabang, hingga toko cabang.

Promotion atau promosi adalah segala upaya untuk meningkatkan brand awareness dan penjualan produk. Promosi dapat dilakukan menggunakan berbagai macam media, dari website, media sosial, surat kabar, radio, televisi, digital ads, media online, video online, hingga podcast. Di era digital ini, mau tidak mau, perusahaan harus bisa menjangkau calon 
konsumen melalui ranah dunia maya. Baik itu melalui media sosial, trafik organik, digital ads, content marketing, ataupun video marketing.

Process adalah prosedur, mekanisme, atau alur yang perlu dilakukan konsumen untuk menggunakan layanan. Untuk lebih mudahnya, process adalah pengalaman konsumen dari awal mengetahui produk sampai melakukan pembelian. Jadi process ini dimulai dari bagaimana konsumen mengetahui produk baik itu dari media sosial, digital ads, blog, atau media lainnya. Ketika konsumen tertarik membeli produk, ia harus melakukan order. Proses ini terus berlangsung sampai konsumen menggunakan barang atau layanan yang dibelinya.

Saluran pemasaran timbul karena lokasi produksi bahan olah karet terdapat di pedesaan yang jauh dari industri pengolahnya (Yuprin, 2009). Strategi pemasaran adalah pola piker pemasaran yang akan digunakan oleh unit bisnis untuk mencapai tujuannya. Strategi pemasaran juga menetapkan suatu target pasar dan suatu bauran pemasaran terkait (Hany Setyorini et al., 2016).

Pemasaran adalah semua kegiatan manusia yang diarahkan untuk memuaskan kebutuhan dan kegiatan melalui proses pertukaran melibatkan kerja, penjual harus mencari pembeli, menemukan dan memenuhi kebutuhan mereka, merancang produksi yang tepat, menentukan harga yang tepat, menyimpan dan mengangkatnya, mempromosikan produk tersebut mensosialisasikan dan sebagainya, semua kegiatan ini merupakan nilai dari pemasaran (Syamsul et al., 2017) Strategi pemasaran yang digunakan sebagai acuan adalah bauran pemasaran (marketing mix). Bauran pemasaran (marketing mix) adalah sekumpulan kegiatan yang saling berhubungan, disusun dengan tujuan untuk mengetahui kebutuhan konsumen, mengembangkan barang yang dibutuhkan, menentukan harganya, mendistribusikan, dan mempromosikannya (Ika et al., 2018)

Tujuan dari penelitian ini adalah untuk menjelaskan proses terjadinya marketing mix yang ada di PT. PANIN DAI-ICHI LIFE INDONESIA secara detail.

\section{METODE}

Metode yang digunakan dalam penelitian ini adalah penelitian kualitatif, yaitu adalah suatu pendekatan yang juga disebut sebagai pendekatan investigasi. Penggunaan metode kualitatif dibutuhkan karena informasi yang tidak hanya dapat memaparkan tetapi juga menggali informasi secara mendalam (Almira \& Suharyanti, 2014). Teknik pengumpulan data dalam penelitian ini bersumber dari data primer dan data sekunder. Pengumpulan data primer dilakukan dengan cara observasi, dan wawancara langsung dengan menggunakan daftar pertanyaan (quisioner), sedangkan data sekunder diperoleh dari beberapa literature dan instansi terkait dalam penelitian ini.Analisis data yang digunakan adalah analisis pemasaran yang berkaitan dengan masalah dan tujuan penelitian (Dokman Marulitua Situmorang, 2019)

\section{HASIL DAN PEMBAHASAN Product}

Ketika produk yang dimiliki semakin kuat dan pondasi kepercayaan dari masyarakat semakin tinggi (trust), maka pendekatan ini lebih cocok digunakan (Raya, 2016). Produk utama yang dipasarkan oleh PANIN DAI-ICHI LIFE adalah produk Asuransi yang bertujuan untuk memberikan perlindungan kepada seluruh masyarakat Indonesia. Produk Asuransi yang ditawarkan sendiri saat ini sangat beragam mulai dari Asuransi Jiwa, Investasi, Asuransi penyakit kritis, Asuransi kecelakaan dan juga Asuransi Kesehatan. Untuk produk Asuransi Jiwa sendiri terdiri dari berbagai macam jenis mulai dari Unit Link, Whole Life serta Termlife yang memberikan pilihan untuk masyarakat diindonesia. Salah satu produk unggulan dari PANIN DAI-ICHI LIFE sendiri yang menjadi andalan dan cukup diminati saat ini adalah Panin Premier Protection dan juga Medical Benefit X. 

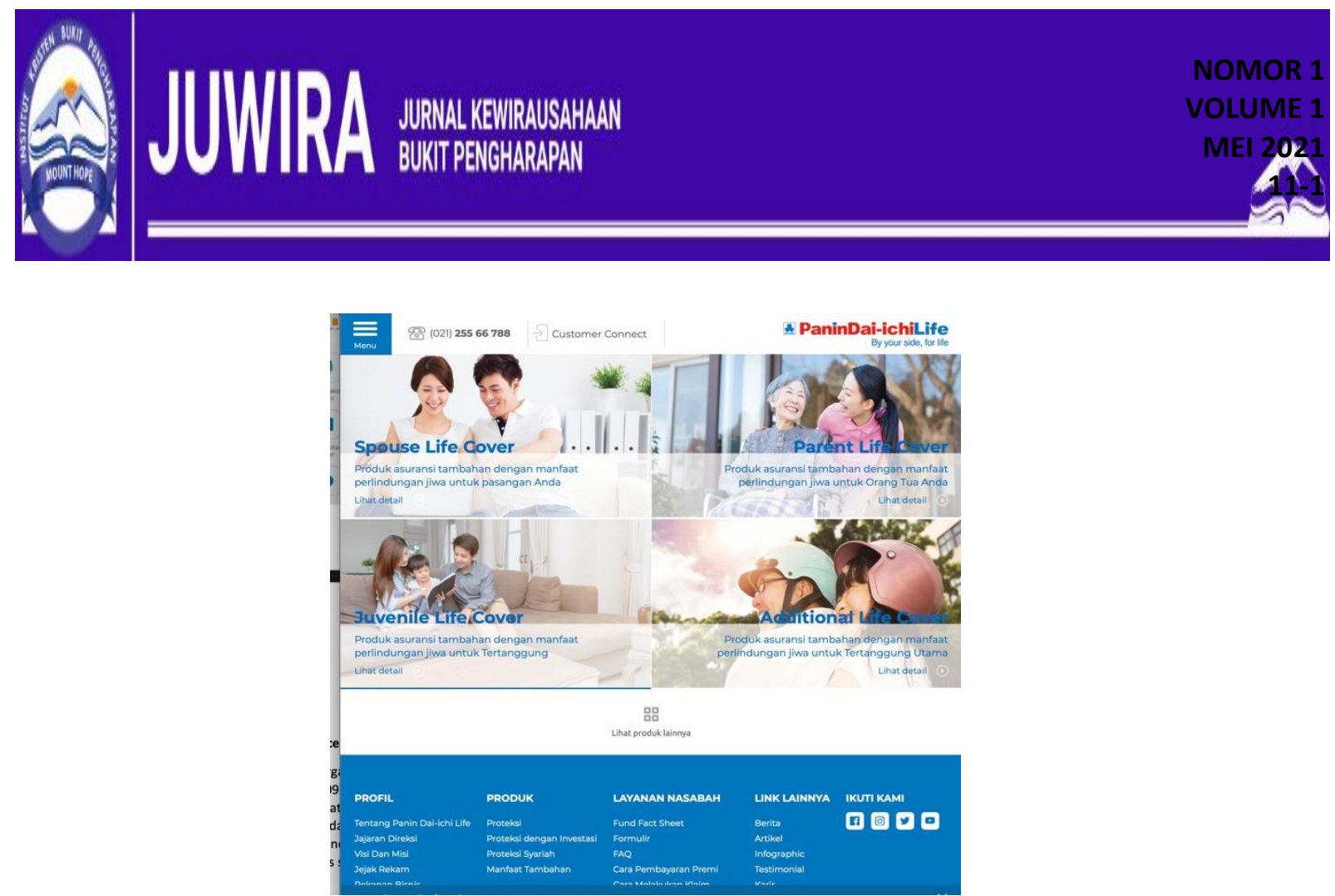

Gambar. 1

\section{Price (Harga)}

Produk yang ditawarkan

PANIN DAI-ICHI LIFE INDONESIA Sendiri memberikan pilihan harga yang terjangkau dan kompetitif dipasar Indonesia sehingga product yang dipasarkan menjadi menarik calon nasabah untuk membeli perlindungan Asuransi Jiwa yang memiliki keunggulan lebih dibandingkan dengan product asuransi lain dan dapat bersaing dengan kompetitor.

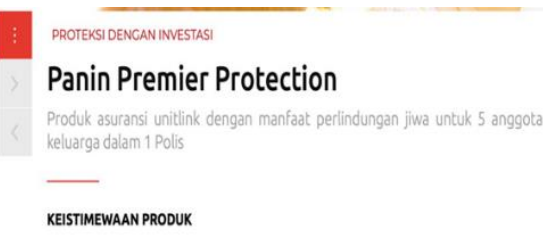

\section{Place (Tempat)}

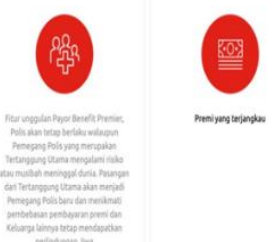

Gambar. 2

Anda tidak harus menempatkan kantor pusat, pabrik, dan toko fisik dalam satu lokasi. Pilihlah lokasi yang ideal dengan mempertimbangkan fungsi dan biaya PANIN DAI-ICHI LIFE INDONESIA berkantor pusat di kota Jakarta tepatnya di Panin Dai-Ichi Life Center, Jl. Letjen S. Parman No. Kav. 91 Jakarta Barat, Indonesia 11420.Dan Panin Dai-Ichi Life saat ini memiliki lebih dari 50 Cabang di seluruh kota di Indonesia. 


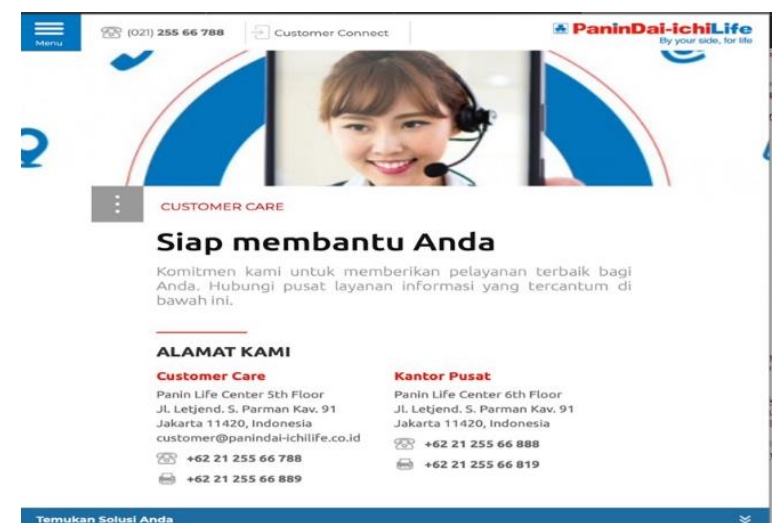

Gambar. 3

Alamat Pelayanan

\section{Promotion}

Media promosi yang digunakan oleh Panin Dai-Ichi Life Indonesia saat ini adalah menggunakan media serta platform digital yang menjadi salah satu media yang dapat diandalkan dalam pemasaran dan promosi. Salah satu media yang digunakan saat ini adalah menggunakan Website yang menjadi salah satu platform digital yang di miliki Panin Dai-Ichi Life.

\section{Physical Evidance}

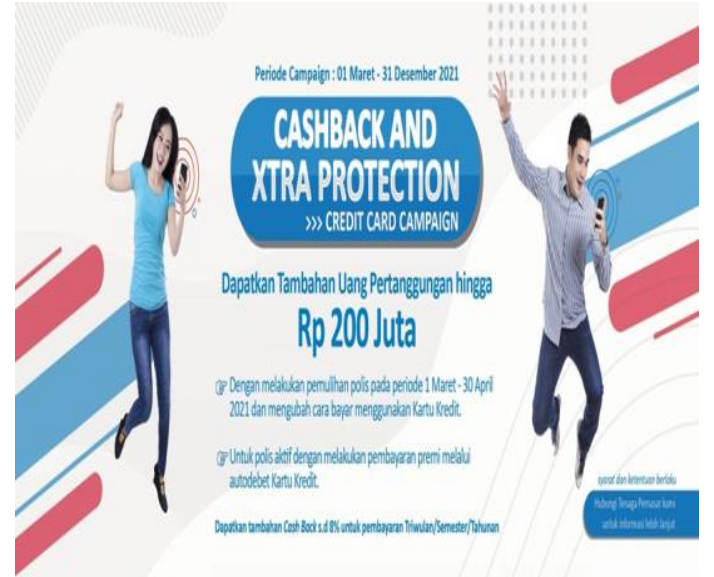

Gambar. 4

Promosi yang dilakukan

Physical evidence atau bukti fisik tidak terbatas pada produk fisik saja. Produk fisik hanyalah salah satu dari sekian banyak physical evidence. Bukti fisik bisa berwujud dalam bentuk logo, brosur, souvenir, akses untuk menghubungi customer service, seragam karyawan, event, dan website resmi. 

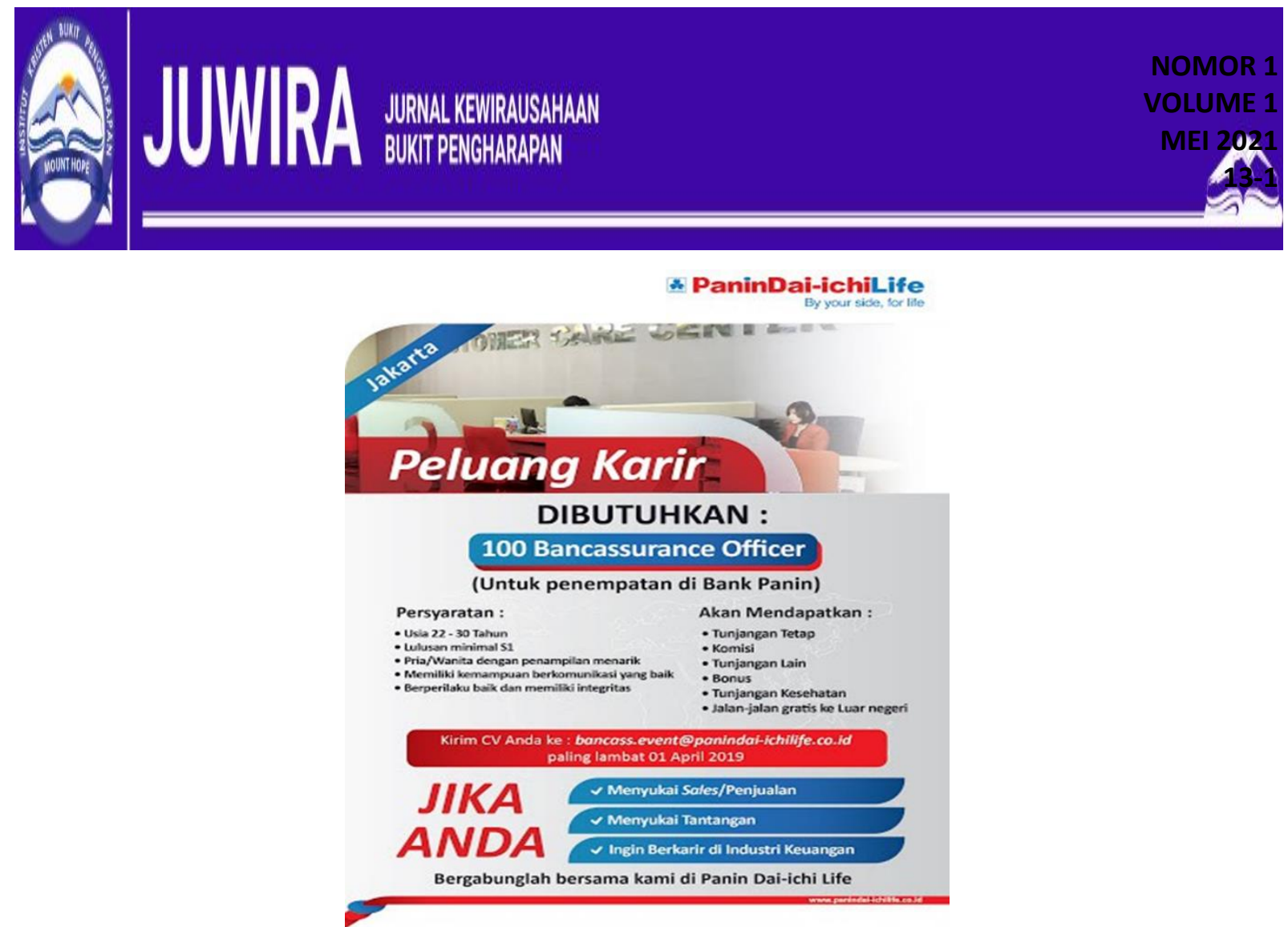

Gambar. 5

Iklan Penawaran kerja

\section{People}

People yang dimaksud di sini adalah sumber daya manusia (SDM) yang menjalankan bisnis, dari direktur sampai staf. SDM adalah aset terpenting dalam bisnis Anda. Salah dalam memilih SDM bisa berakibat fatal pada bisnis. Menjadi bagian dari Panin Dai Ichi Life sebagai Assistant Manager untuk Dept. Business Development, Relatonship and Support Panin group.

\section{Direksi}

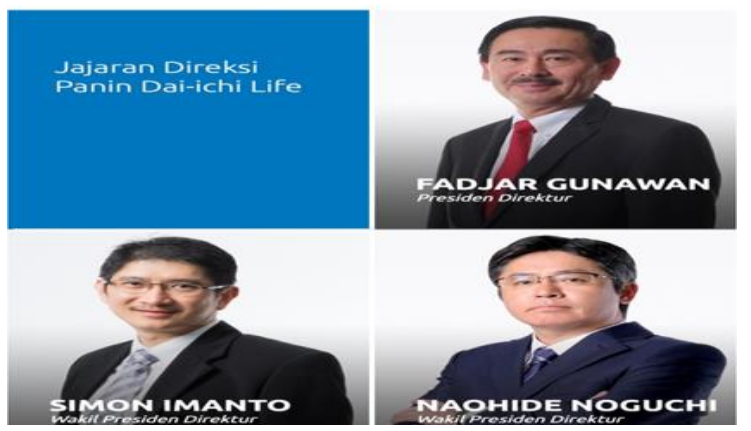

Gambar. 6

\section{Process (Proses)}

\section{Jajaran Direksi}

Hal terpenting dalam elemen ini adalah konsistensi. Produk atau layanan harus konsisten. Apa yang di iklankan harus konsisten dengan apa yang didapatkan oleh konsumen. Inkonsistensi produk akan merusak pengalaman konsumen dan kemungkinan terburuknya konsumen tidak mau menggunakan produk/layanan perusahaan kita lagi. 


\section{KESIMPULAN}

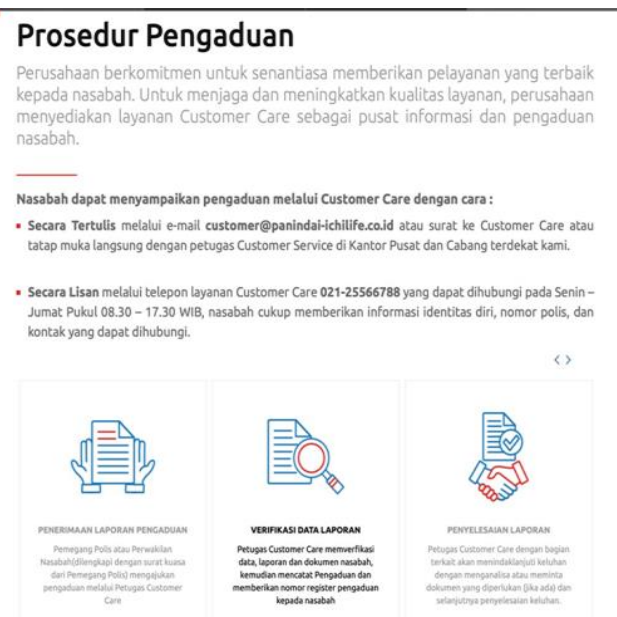

\section{Gambar. 7 \\ Proses Pengaduan}

Strategi penerapan Marketing Mix di PT. PANIN DAI-ICHI LIFE INDONESIA Sudah sesuai dengan metode strategi hal itu bisa kita lihat dari Produk utama yang dipasarkan oleh PANIN DAI-ICHI LIFE adalah produk Asuransi yang bertujuan untuk memberikan perlindungan kepada seluruh masyarakat Indonesia. Media promosi yang digunakan oleh Panin Dai-Ichi Life Indonesia saat ini adalah menggunakan media serta platform digital. Dan begitu juga dari sisi harga, proses.

\section{DAFTAR PUSTAKA}

Almira, S. K., \& Suharyanti. (2014). Implementasi Strategi Marketing Public Relations Dalam Pengelolaan Citra Merek. Journal Communication Spectrum, 4(1), 57-71.

Dokman Marulitua Situmorang. (2019). The Effect Of Taxpayer Awarenes And Fiskus Service On Performance Of Tax Revenue With Taxpayer Compliance As Intervening Variables (Case Study Of Individual Taxpayers Registered At The Medan City Kpp Pratama). Management And Sustainable Development Journal, 1(1), 26-37.

Hany Setyorini, Mas'ud Effendi, \& Santoso, I. (2016). Marketing Strategy Analysis Using Swot Matrix And Qspm (Case Study: Ws Restaurant Soekarno Hatta Malang). Industria: Jurnal Teknologi Dan Manajemen Agroindustri, 5(1), 46-53. Https://Doi.Org/10.21776/Ub.Industria.2016.005.01.6

Ika, P. R., Prabandari, S., \& Prabasiwi, A. (2018). Implementasi Strategi Bauran Pemasaran (Marketing Mix) Pada Obat Bebas Di Apotek "Nurbunda" Dari Perspektif Etika Kefarmasian. Parapemikir: Jurnal Ilmiah Farmasi, 7, 187-191. Http://Ejournal.Poltektegal.Ac.Id/Index.Php/Parapemikir/Article/Viewfile/740/605

Raya, M. K. F. (2016). Marketing Jasa Di Institusi Pendidikan ( Analisis Pemasaran Dalam Pendidikan ). Falasafa, 7(1), 21.

Syamsul, R., Astina, C., \& Fajri, N. (2017). Implementasi Marketing Mix Dalam Upaya Kemajuan Usaha Butik Muslimah Di Kota Langsa. Jurnal Ilmiah Mahasiswa, 1(1), 1-22. Yuprin. (2009). Analisis Pemasaran Karet Di Kabupaten Kapuas. Jurnal Wacana, 12(3). 